\title{
ORIENTAÇÕES PARA O USO DIDÁTICO DE MATERIAIS NA ESCOLA PRIMÁRIA: UM ESTUDO EM REVISTAS PEDAGÓGICAS (1891 - 1916)
}

\author{
Rosimeire Borges \\ Universidade do Vale do Sapucaí \\ rasborges3@gmail.com \\ Aparecida Rodrigues Silva Duarte \\ Universidade do Vale do Sapucaí \\ aparecida.duarte6@gmail.com \\ Érica Nadir da Cruz \\ Universidade do Vale do Sapucaí \\ ericaandrade97@yahoo.com.br
}

\begin{abstract}
RESUMO
Este estudo histórico analisou artigos de revistas pedagógicas, publicadas em diferentes estados brasileiros, no período 1891 a 1916. Nestas fontes, buscou-se conhecer recomendações e orientações para o uso didático de materiais nas aulas de aritmética da escola primária. Observouse que os autores destes artigos sugeriram que os professores leitores utilizassem diversificados materiais em suas aulas de aritmética, apresentando modelos de atividades que envolvessem os alunos na observação, comparação e manipulação desses materiais, na resolução de exercícios e problemas, de forma a auxiliá-los na compreensão dos conceitos aritméticos estudados. Em suma, estes artigos disseminaram fundamentos do método intuitivo para as escolas primárias brasileiras naquele período.
\end{abstract}

Palavras-chave: Escola primária. Método intuitivo. Revistas pedagógicas.

\section{GUIDELINES FOR USING DIDACTIC MATERIALS IN ELEMENTARY SCHOOL: A STUDY IN PEDAGOGICAL JOURNALS (1891-1916)}

\begin{abstract}
This historical study analysed articles of pedagogical journals, published in different Brazilian states, from 1891 to 1916 . In these sources, the research work sought to know recommendations and guidelines for the didactic use of materials in primary school arithmetic classes. The study concluded that the authors of these articles suggested that teachers readers used diverse materials in their arithmetic classes, presenting models of activities that would involve the students in the observation, comparison and manipulation of these materials to resolve exercises and problems, in order to help them understand the arithmetic concepts studied. In short, these articles disseminated the foundations of the intuitive method for Brazilian elementary schools at that time.
\end{abstract}

Keywords: Elementary school. Intuitive method. Pedagogical journals. 


\section{ORIENTACIONES PARA EL USO DIDÁCTICO DE MATERIALES EN LA ESCUELA PRIMARIA: UN ESTUDIO EN REVISTAS PEDAGÓGICAS (1891 - 1916)}

\section{RESUMEN}

Este estudio histórico analizó artículos de revistas pedagógicas, publicadas en diferentes estados brasileños, en el período 1891 a 1916. En estas fuentes, se buscó conocer recomendaciones y orientaciones para el uso didáctico de materiales en las clases de aritmética de la escuela primaria. Se concluye que los autores de estos artículos sugirieron a los profesores lectores que utilizasen diversos materiales en sus clases de aritmética, presentando modelos de actividades que involucraran a los alumnos en la observación, comparación y manipulación de esos materiales en la resolución de ejercicios y problemas, de forma a auxiliar en la comprensión de los conceptos aritméticos estudiados. En suma, estos artículos diseminaron fundamentos del método intuitivo para las escuelas primarias brasileñas en aquel período.

Palabras clave: Escuela primaria. Método intuitivo. Revistas pedagógicas.

\section{PRINCIPES DIRECTEURS POUR L'UTILISATION DIDACTIQUE DU MATERIEL A L'ECOLE PRIMAIRE: UNE ETUDE DANS DES REVUES PEDAGOGIQUES (1891 -} 1916)

\section{RÉSUMÉ}

Cette étude historique a analysé des articles de revues pédagogiques publiées de 1891 à 1916 dans différents États du Brésil. Ces sources visaient à connaître les recommandations et les principes directeurs relatifs à l'utilisation didactique des matériaux dans les classes d'arithmétique de l'école primaire. Les auteurs de ces articles ont suggéré à leurs lecteurs d'utiliser différents matériaux dans leurs cours d'arithmétique, en présentant des modèles d'activités impliquant les étudiants dans a l'observation, la comparaison et la manipulation de ces matériaux lors de la résolution d'exercices et de problèmes, afin de les aider à comprendre la concepts arithmétiques étudiés en classe. En résumé, ces articles ont diffusé les bases de la méthode intuitive pour les écoles primaires brésiliennes au cours de la période de référence.

Mots-clés: École primaire. Méthode intuitive. Revues pédagogiques.

\section{INTRODUÇÃO}

Durante o século XIX ocorreu a consolidação entre materiais manipuláveis para uso didático e renovação pedagógica em vários países ocidentais, ocasião em que novas modalidades de organização escolar foram testadas, com vistas à universalização do ensino (SOUZA, 2013). Uma prática pedagógica que abrangeu o uso de materiais manipuláveis para o ensino de aritmética 
nos primeiros anos escolares daquela época é referida por Valente (2015), que mostra como foi posta a necessidade de aparelhar a escola com materiais por meio dos quais o professor pudesse realizar o ensino concreto ${ }^{1}$.

Com o objetivo de analisar as recomendações e orientações para o uso didático de materiais nas aulas de aritmética da escola primária, este estudo, de cunho histórico, tomou artigos de revistas pedagógicas publicadas em diferentes estados brasileiros no período 1891 a 1916 como fontes. Buscou-se encontrar indícios que auxiliem na compreensão de como o uso desses materiais passou a fazer parte da cultura escolar naquele período. As revistas pedagógicas selecionadas para este estudo estão presentes em um Repositório de Conteúdos Virtuais, especificamente na comunidade História da Educação Matemática².

Optou-se por considerar as revistas pedagógicas como fontes de pesquisa, considerando o entendimento de Carvalho (2006, p. 142), para quem elas disseminam orientações para a prática pedagógica dos docentes, constituindo-se em objetos culturais que detêm "as marcas de sua produção, circulação e usos", e Valente (2015, p. 599), que, ao tratar da relevância das revistas pedagógicas como fontes, evidencia que estas podem auxiliar nas análises de "orientações veiculadas aos professores num dado tempo por autoridades do ensino, por especialistas da Educação e mesmo pelos próprios professores, dentre outros autores que escrevem nesses periódicos".

A delimitação temporal inicial deste estudo justifica-se por indicar o início de um período em que se fizeram presentes as ideias de modernização pedagógica advindas da vaga internacional do ensino intuitivo. Foi um movimento impulsionado pelas críticas à pedagogia que se baseava na aprendizagem de forma exclusiva na memória, priorizando a abstração e a repetição no lugar da compreensão dos conteúdos. Por sua vez, a nova pedagogia intuitiva baseava-se na renovação do ensino com foco na adoção do método intuitivo de ensino, que deveria ser racional, ativo e concreto

\footnotetext{
${ }^{1}$ Para Valente (2015, p.598), "Essa expressão, bem como outras derivações dela - ensino concreto, ensino pelo concreto, concretização, trabalho no concreto, material concreto - parece designar, no cotidiano das escolas, algo como uma reação, ou mesmo uma aversão à abstração,[...] E, neste caso, a abstração é considerada como algo fora da vida, do real."

${ }^{2}$ Consiste em uma "base de dados aberta na internet, alimentada por diferentes estados e grupos de pesquisa brasileiros com documentação basilar para a história da educação matemática", com apoio da Universidade Federal de Santa Catarina (VALENTE, 2017, p. 601). Disponível em: https://repositorio.ufsc.br/handle/123456789/1769. Acesso em: 12 mar. 2019.
} 
(VALDEMARIN, 2004). Além disso, a década de 1890 marca o início da criação dos grupos escolares no Brasil. Já a delimitação final deste estudo, o ano de 1916 sinaliza os primeiros rumores do Movimento da Escola Nova na educação brasileira. Valente (2015, p. 199-200) refere-se ao período de início desse movimento no Brasil nos seguintes termos: "uma nova era anuncia-se a partir de finais dos anos 1920. Uma nova pedagogia buscará sobrepor-se àquela intuitiva. [...] referência fundamental nos debates, em meio à emergência do chamado movimento da Escola Nova".

Em períodos de reformas educativas, uma grande quantidade de documentos e materiais é produzida e podem ser mobilizadas como fontes de pesquisa, como por exemplo: textos oficiais, manuais didáticos, documentos orientadores do currículo, revistas pedagógicas que são elaborados com a finalidade de dar orientações para a prática pedagógica. Para Valente (2015, p. 599), nas revistas pedagógicas podem estar discursos que buscam convencer os professores a utilizar novas práticas pedagógicas e “a moderna pedagogia impõe a ‘concretização' no ensino de aritmética para os primeiros anos escolares. Essa é uma das faces reveladas nas orientações para professores que ensinam matemática em tempos da vaga pedagógica do ensino intuitivo".

Considerando, portanto, que as revistas pedagógicas fazem circular orientações de metodologias de ensino para os docentes das séries iniciais de escolaridade, e essas metodologias, por diversas vezes, podem estar acompanhadas de sugestões de uso didático de materiais na escola primária para apoio nas aulas, emergiram as questões norteadoras deste estudo: quais foram as orientações para o uso didático de materiais no ensino da aritmética no curso primário dadas por autores de artigos publicados em revistas pedagógicas brasileiras no período compreendido entre 1891 e 1916? Quais foram as justificativas desses autores quanto à orientação para uso didático desses materiais?

Retoma-se, assim, que o objetivo deste estudo é analisar, por meio de artigos publicados em revistas pedagógicas brasileiras (1891-1916), as recomendações e orientações para o uso didático-pedagógico de materiais nas aulas de aritmética da escola primária, que passaram a ser incorporadas à cultura escolar nos primeiros anos escolares. Em outras palavras, como a representação da necessidade de uso didático-pedagógico de materiais nas aulas de aritmética nos primeiros anos escolares foi sendo construída por esses autores. 
A construção do sentido desses artigos publicados no período em estudo pode-se dar ao cruzarmos a história das práticas e a história das representações inscritas nos textos ou produzidas pelos indivíduos. Assim, utilizamos o conceito de representação conforme salientado por Roger Chartier, para quem o mundo real é representado de acordo com determinações de grupos sociais:

[...] pode pensar-se uma história cultural do social que tome por objeto a compreensão das formas e dos motivos - ou, por outras palavras, das representações do mundo social - que, à revelia dos atores sociais, traduzem as suas posições e interesses objetivamente confrontados e que, paralelamente, descrevem a sociedade tal como pensam que ela é, ou como gostariam que fosse. (CHARTIER, 1990, p. 19).

Nesta perspectiva, é preciso considerar o processo por meio do qual os artigos publicados nas revistas pedagógicas durante o período de vigência da pedagogia intuitiva tiveram significado para os autores que se apropriaram das propostas dessa modernização do ensino. Eles tiveram por incumbência a produção de orientações didático-pedagógicas para os professores que atuavam nas primeiras séries de escolaridade, leitores dessas revistas. Necessário se faz, assim, utilizar o conceito de apropriação que, segundo Chartier (1991, p. 180), "visa uma história social dos usos e das interpretações, referidas a suas determinações fundamentais e inscritas nas práticas específicas que as produzem".

\section{A PEDAgOgIA INTUITIVA, OS GRUPOS ESCOLARES E A LIÇÃO DE COISAS}

Em finais do século XIX, ganhou força um movimento de renovação pedagógica que contrariava “[...] o caráter abstrato e pouco utilitário da instrução, prescrevendo- lhe novo método de ensino, novos materiais, a criação de museus pedagógicos, variação de atividades, excursões pedagógicas, estudo do meio, entre outras", a pedagogia intuitiva (VALDEMARIN, 2004, p. 104). Foi quando o uso do método intuitivo no ensino consistiu em um aspecto dessa renovação pedagógica pretendida.

O método intuitivo baseava-se na aprendizagem do aluno por meio dos sentidos, com a percepção de sons, cores, formas, relações, dentre outros aspectos (ARANHA, 1996). De acordo com Valdemarin e Pinto (2010, p. 166), esse método fundamentava-se na experimentação e era 
apresentado como um "recurso pedagógico para reverter o caráter abstrato e pouco utilitário do ensino", aliando-se a "novos materiais (gravuras, coleções, objetos de madeira, papel e linha, caixa de tintas etc.)".

A aplicação do método intuitivo, conforme era proposto pelos seus idealizadores, deveria ser fundamentalmente prática, o que demandava um amplo “conjunto de materiais de apoio, espaço físico, preparo didático dos professores para estimular os sentidos dos alunos e promover aprendizagens significativas" (VALDEMARIN; PINTO, 2010, p. 183). Neste sentido, um dos recursos empregados no método intuitivo era a "lição de coisas", que consistia em:

[...] um procedimento de ensino, uma das aplicações do método intuitivo [...], mas deveria estar presente em todas as atividades de ensino em todo o período escolar, pois envolve tudo que se refere à vida e a todos os fenômenos da natureza. Isto é, apresentado como início e o fim de todos os estudos experimentais, como lições de observação, de informação, de palavras. (BASTOS, 2013, p. 234).

Desta forma, a lição de coisas deveria se fazer presente nas práticas educativas, posto que compreendia o que estivesse relacionado aos acontecimentos naturais e à vida dos alunos, compelindo-os a ver, tocar, distinguir, medir, comparar e nomear coisas (BASTOS, 2013).

Na perspectiva de um ensino pelos sentidos e de uma educação para a aprendizagem dos sentidos, a prioridade para a observação nas práticas escolares evidenciou-se como significativa. Assim, essa valorização do método intuitivo e o ensino através da lição de coisas acabaram por estimular uma diversificada produção de recursos didáticos nesse período (BASTOS, 2013).

$\mathrm{Na}$ América Latina, um dos pensadores que propagaram as ideias do método intuitivo foi o francês Ferdinand Buisson ${ }^{3}$. Em 1878, Buisson participou da Exposição de Paris, referindo-se à valorização da educação popular por Pestalozzi ${ }^{4}$, que defendia a espontaneidade do aluno com base em sua intuição psicológica. Ele atribuiu a Marie Pape Carpentier a responsabilidade pela

\footnotetext{
${ }^{3}$ Buisson (1841- 1932) foi um dos intelectuais e educadores franceses que influenciaram os escritos e atividades elaborados com autoria de intelectuais do Brasil.

${ }^{4}$ Em conformidade com Valente (2015, p. 204), "para Pestalozzi, ícone da pedagogia intuitiva, [...], o elementar é psicológico e empírico (ele refere-se ao um sujeito existencial e sensível). Para Pestalozzi, trata-se de partir da existência das coisas para ter acesso às palavras, de acordo com mecanismos considerados naturais".
} 
divulgação desse método e pela elaboração de materiais didáticos como a "Caixa de Lição de Coisas"5 e a "Lanterna Mágica"6 (ARANHA, 1996).

Para Delon (1887, p. 5 apud BASTOS, 2013, p. 234), a lição de coisas era considerada uma ferramenta de educação e instrução, e, segundo suas palavras, só a lição de coisas poderia colocar os alunos:

[...] na presença dos fatos materiais, com realidades visíveis e tangíveis, não mais de abstrações [...] Mas é do ponto de vista educativo que a lição de coisas tem mais valor. Ela tem essencialmente por objetivo desenvolver e exercitar os orgãos, a inteligência, o julgamento; de suscitar o espírito de observação e pesquisa, a iniciativa pessoal; comparar com outros objetos, generalizar suas observações, raciocinar e concluir. Apela para todas as faculdades e operações de sua inteligência.

Como o método intuitivo era para ser aplicado a todas as áreas de conhecimento, iniciariam as lições sobre as formas geométricas, por exemplo, utilizando objetos presentes no cotidiano das crianças, e, progressivamente, chegariam a objetos industrializados e elementos naturais (VALDEMARIN, 2000). Esses objetos, segundo palavras de Saviani (2005, p. 8), envolviam “[...] peças do mobiliário escolar; quadros negros parietais; caixas para ensino de cores e formas; quadros do reino vegetal, gravuras, objetos de madeira, cartas de cores para instrução primária; aros, mapas, linhas, diagramas [...]", e assim o conteúdo ensinado com o nome de lições de coisas iria veicular a valorização do progresso científico e das aplicações relacionadas a esses conteúdos.

No que tange ao ensino de Aritmética no primário, ao considerar o desenvolvimento das faculdades cognitivas da criança, a instrução escolar deixou de ensinar os elementos da ciência, deslocando-se dos campos dos saberes elementares, para um ensino dos rudimentos aritméticos imprescindíveis em situações da vida prática. Era um ensino voltado para a vida da criança, e foi a partir dessas transformações que se se deu a configuração de uma aritmética intuitiva (PINHEIRO; VALENTE, 2018). E a escola elementar, baseada na intuição, ensinava essa Aritmética e tinha como propósito orientar o ensino em consonância com o desenvolvimento da inteligência da criança de modo que criasse hábitos de raciocínio (OLIVEIRA, 2017).

\footnotetext{
${ }^{5}$ Essa caixa de Mme. Papa-Carpintier continha três compartimentos e subcompartimentos, onde estão classificadas as amostras dos materiais que o homem emprega para satisfazer suas necessidades: vestuário, alimentação, habitação e metais (BASTOS, 2010).

${ }^{6}$ Era um projetor de imagens.
} 
Assim, iniciava-se uma preferência pelo ensino intuitivo da Aritmética na escola primária, em detrimento do estudo a partir de noções abstratas de números e fórmulas exprimindo suas relações. Nesse sentido, Valente (2008) salienta que o método intuitivo foi apropriado pelo ensino do cálculo elementar na escola primária brasileira, onde, até então, reinava a memorização da tabuada como método essencial de aprendizagem das operações elementares aritméticas. Para esse pesquisador:

[...] A chegada do ideário do ensino intuitivo, como ensino ativo, experimental e concreto construiu uma representação para o passado do ensino de Aritmética no primário profundamente negativa. Um ensino abstrato, com uso quase exclusivo de processos de memorização, sem utilidade. Tal representação, ao que parece, é decalcada daquela que desencadeou o movimento renovador pedagógico e que constituiu o que Buisson chamou de consciência pedagógica de uma época. Também ela, a Aritmética, imersa nessa escola ineficiente, deveria ser transformada. Ensinada de outro modo, com materiais onde o ensino fosse o mais concreto possível. (VALENTE, 2008, p. 3).

As inovações educacionais alardeadas eram foco de debates relativos aos métodos de ensino na década de 1890, quando se almejava uma modernização nas instituições de ensino. Para Valdemarin e Pinto (2010, p. 170), "tais inovações consistiriam, efetivamente, na divulgação e implantação de métodos de ensino diferenciados, nas práticas de professores, no uso de materiais diversos, na organização e construção de prédios escolares".

No ano de 1890, a Reforma Benjamin Constant, instituída pelo Decreto nº 981/1890, veio garantir um ensino primário oficial, gratuito e laico, com distinção de escolas primárias para ambos os sexos e valorização da família face à educação da criança. Com a intenção de organizar o sistema educacional, a reforma propunha um processo educativo sob o modelo seriado e influenciou a ampliação e ordenação dos currículos das escolas brasileiras para que fossem incluídas disciplinas científicas (CURY, 2009).

Estas ações em prol da modernização do ensino primário marcaram uma "década de criação de uma nova forma de organização do curso primário: os Grupos Escolares”, que vieram substituir as escolas isoladas ${ }^{7}$. Esses grupos foram criados inicialmente no estado de São Paulo e, juntamente

\footnotetext{
${ }^{7}$ Nas escolas isoladas, o professor ministrava aulas para uma turma formada por alunos em diferentes níveis de aprendizagem (SAVIANI, 2004).
} 
com os grupos escolares, adveio a seriação e a propagação do método intuitivo nos primeiros anos de escolaridade (VALENTE, 2015, p. 198). Saviani discorre sobre a seriação da escola, quando as "escolas isoladas, uma vez reunidas, deram origem, no interior dos grupos escolares, às classes que, por sua vez, correspondiam às séries anuais" (SAVIANI, 2004, p. 25).

Nesse período, os grupos escolares constituíam "todo um conjunto de saberes, de projetos político-educativos, e punham em circulação o modelo definitivo da educação do século XIX: o das escolas seriadas" (FARIA FILHO; VIDAL, 2000, p. 25) que, além de programar para um futuro idealizado, formariam as pessoas para uma nação progressista. E foi a partir de 1893, que outros grupos escolares foram criados em diferentes estados do Brasil e, de maneira geral, essa criação "seguiu a evolução da organização dos sistemas públicos estaduais de ensino primário", conforme evidenciam Faria Filho e Vidal (2000, p. 28). Segundo Saviani (2004, p. 28), em 1910 o estado de São Paulo já contabilizaria 24 grupos escolares na capital e 77 no interior e, a partir daí, com a aceitação desse modelo pela organização pedagógica da escola primária, os grupos escolares se propagaram por todo o país.

Em 1901, no Brasil, foi instituída a Reforma Epitácio Pessoa, que intentou propiciar a concretização dos ideais reformistas de Benjamin Constant, considerados adequados, porém com delineamentos mais genéricos, dando prioridade à formação secundária, fundamentada na consolidação do modelo educacional com estrutura seriada (SEKI; MACHADO, 2018). Em 1911, ocorreu no Brasil a Reforma Rivadávia Correia, pelo Decreto nº 8.659/1911, que instituiu a Lei Orgânica do Ensino Superior e Fundamental. Essa reforma causou uma desordem na educação do país, e ficou marcada pela insatisfação em relação à negligência do Estado em relação a educação. Em 1915, a Reforma Carlos Maximiliano veio impulsionar novamente a educação brasileira, trazendo de volta a interferência do Estado na educação (BOMENY, 2010).

Bomeny (2010) assegura que a década de 1910 despertou no Brasil um entusiasmo com a adesão coletiva à bandeira da educação, antecedendo assim a década de 1920, que seria palco de diversas reformas educativas em diferentes estados brasileiros. Essas reformas influenciariam o Movimento da Escola Nova, vindo sobrepor-se à pedagogia intuitiva, conforme já referido. A Escola Nova registraria um otimismo pedagógico com relação ao poder da educação que se fundamentava no desenvolvimento científico da nova pedagogia, que tinha como finalidade a formação do ser humano para uma sociedade em transformação. 
Encerra-se aqui, a descrição do momento social em que circularam os artigos das revistas pedagógicas analisadas, pois, para Chartier (1991, p. 180), é preciso apresentar a área social "em que circulam um corpus de textos, uma classe de impressos, uma produção, ou uma norma cultural". Considerou-se, portanto, que os artigos produzidos naquele período atribuíram significado às propostas da pedagogia intuitiva para os professores da escola primária, leitores das revistas pedagógicas.

\section{SOBRE AS REVISTAS PEDAGÓGICAS ANALISADAS}

Os periódicos pedagógicos integram os diferentes meios de comunicação da imprensa pedagógica, que é, em grande parte, responsável por divulgar temas que são discutidos e produzidos na escola. Trata-se de um "espaço de afirmação de correntes de acção e de pensamento educacional" (NÓVOA, 1993, p. XXXII) que propicia maior entendimento sobre o histórico da educação.

Assim, conforme já referido, para este estudo foram privilegiadas revistas pedagógicas brasileiras, publicadas no período que pode ser considerado da vaga intuitiva, 1891-1916, que contêm artigos cujo tema é o ensino de aritmética, presentes no Repositório de Conteúdos Virtuais da Universidade Federal de Santa Catarina. Entretanto, conforme observa Valente (2017), "Há poucas publicações em finais do século XIX de periódicos pedagógicos. Encontram-se textos significativos vindos da antiga capital (Salvador, Bahia), da Capital Federal (Rio de Janeiro) e de São Paulo".

Em um primeiro momento, na entrada na base de dados do Repositório Virtual da Universidade Federal de Santa Catarina, foram considerados os periódicos encontrados por ordem cronológica, com análise um a um, diretamente nas páginas de cada uma das revistas encontradas, com seus artigos sobre a aritmética publicados em seus respectivos números. O número de artigos por revista(s) encontrada(s) de cada estado é: um artigo na Revista A Escola do Pará; dois artigos na Revista A Eschola Publica de São Paulo; dois artigos na Revista do Ensino de São Paulo; dois artigos na Revista Educação de São Paulo; dois artigos na Revista Pedagógica do Rio de Janeiro, um artigo na Revista A Escola do Rio de Janeiro; cinco artigos na Revista do Ensino Primário da 
Bahia e três artigos na Revista do Ensino de Alagoas. Observa-se que, durante todo o período, apenas 18 artigos encontrados referem-se ao ensino da aritmética.

Após a leitura cuidadosa desses artigos, foram selecionados somente aqueles que abordam o uso didático de materiais em aulas de aritmética na escola primária, somando 12 os artigos analisados neste estudo, que estão apresentados no quadro 1. Como se pode observar, são escassos os números de revistas desse período cujos artigos apresentaram sugestões para os professores leitores relativas ao uso didático de materiais para o ensino de Aritmética, nos anos iniciais de escolaridade. Dos diferentes estados brasileiros em que esses periódicos foram publicados, no período em estudo, a maioria é do estado da Bahia (antiga capital), Rio de Janeiro (naquela época capital federal do Brasil) e São Paulo (berço de criação dos grupos escolares).

QUADRO 1 - Relação de artigos analisados

\begin{tabular}{|c|l|}
\hline $\begin{array}{c}\text { Ano/ } \\
\text { mês }\end{array}$ & $\begin{array}{l}\text { Título do Artigo } \\
\text { Autor } \\
\text { Revista }\end{array}$ \\
\hline $\begin{array}{c}1891 / \\
\text { maio }\end{array}$ & $\begin{array}{l}\text { Instruções para a organização do ensino das escolas primárias. } \\
\text { (Sem autor) } \\
\text { Revista do Ensino, Maceió, v. 1, n. 1, p. 5-16, maio, 1891. }\end{array}$ \\
\hline $\begin{array}{c}1892 / \\
\text { nov. }\end{array}$ & $\begin{array}{l}\text { Nos etiam pro causa nóstra pugnamos. } \\
\text { Argemiro Cavalcante } \\
\text { Revista do Ensino Primário, Salvador, v. 1, n. 1, p. 1-9, nov. 1892a. }\end{array}$ \\
\hline $\begin{array}{c}1892 / \\
\text { dez. }\end{array}$ & $\begin{array}{l}\text { Consideraçóes sobre o ensino de leitura e arithmetica } \\
\text { Argemiro Cavalcante } \\
\text { Revista do Ensino Primário, Salvador, v. 1, n. 02, p. 21-23, dez. 1892b. }\end{array}$ \\
\hline $\begin{array}{c}1893 / \\
\text { jul. }\end{array}$ & $\begin{array}{l}\text { O ensino de Arithmetica } \\
\text { Pedro Celestino } \\
\text { Revista do Ensino Primário, Salvador, v. 1, n. 9, p. 164-166, jul. 1893a. }\end{array}$ \\
\hline $\begin{array}{c}1893 / \\
\text { ago }\end{array}$ & $\begin{array}{l}\text { O ensino de Arithmetica } \\
\text { Pedro Celestino } \\
\text { Revista do Ensino Primário, Salvador, v. 1, n. 10, p. 185-186, ago. 1893b. }\end{array}$ \\
\hline $\begin{array}{c}1893 / \\
\text { out. }\end{array}$ & $\begin{array}{l}\text { O ensino de Arithmetica } \\
\text { Pedro Celestino } \\
\text { Revista do Ensino Primário, Salvador, v. 1, n. 12, p. 218-220, out. 1893c. }\end{array}$ \\
\hline $1893 /$ & $\begin{array}{l}\text { Observação aos professores ou adjuntos que se occupam do ensino de arithmetica nas } \\
\text { classes elementares das escolas do }{ }^{\circ} \text { graus } \\
\text { jul. }\end{array}$ \\
\hline $\begin{array}{c}\text { J. F. Velho da Silva } \\
\text { Revista Pedagógica, Rio de Janeiro, p. 287-302, 1893. }\end{array}$ \\
\hline $1893 /$ & $\begin{array}{l}\text { Manual de Methodos } \\
\text { Kiddle; Harrison; Calkins } \\
\text { Revista Pedagógica, Rio de Janeiro, n. 25/26/27, p. 215-227, set. 1893. }\end{array}$ \\
\hline
\end{tabular}




\begin{tabular}{|c|l|}
\hline $\begin{array}{c}1893 / \\
\text { jul. }\end{array}$ & $\begin{array}{l}\text { Arithmetica elementar } \\
\text { Oscar Thompson } \\
\text { A Eschola Publica, São Paulo, v. 1, n. 1, p. 5-6, jul., } 1893 .\end{array}$ \\
\hline $\begin{array}{c}1896 / \\
\text { dez. }\end{array}$ & $\begin{array}{l}\text { Arithmetica } \\
\text { Arnaldo Barreto } \\
\text { A Eschola Publica, São Paulo, v. 1, n. 4, p. 309-313, dez. } 1896 .\end{array}$ \\
\hline $\begin{array}{c}1902 / \\
\text { abr. }\end{array}$ & $\begin{array}{l}\text { Cartas de Parker para o ensino de aritmética nas escolas primárias } \\
\text { Joaquim Luís Brito } \\
\text { Revista de Ensino, São Paulo, v. 1, n. 1, p. 35-46, abr. 1902. }\end{array}$ \\
\hline $\begin{array}{c}1916 / \\
\text { dez. }\end{array}$ & $\begin{array}{l}\text { Aritmetica Preliminar } \\
\text { Flávio Lopes Monteiro } \\
\text { Revista de Ensino, São Paulo, v. 15, n. 3, p. 29-32, dez. } 1916 .\end{array}$ \\
\hline
\end{tabular}

Fonte: https://repositorio.ufsc.br/

Foi possível verificar diferentes abordagens e diferenciadas orientações didáticopedagógicas dos professores autores desses artigos, revelando um esforço para que suas representações fossem apropriadas pelos professores leitores para a orientação de suas práticas na escola primária, o que será tratado a seguir.

\section{AS REVISTAS PEDAGÓGICAS E O USO DIDÁTICO DE MATERIAIS NO ENSINO DE ARITMÉTICA}

Os artigos das revistas pedagógicas analisados neste estudo, conforme já mencionado, foram publicados de 1891 a 1916. Apresentam orientações didático-pedagógicas abordando o uso de materiais manipuláveis nas aulas de aritmética da escola primária na última década do século XIX e no início dos anos 1900.

A começar pelo artigo "Instruções para a organização do ensino das escolas primárias", publicado na Revista do Ensino de Alagoas, em seu número 1, de maio de 1891, apresentou instruções referentes às disciplinas que comporiam o currículo na escola primária e conteúdos aritméticos, discorrendo sobre as operações fundamentais, a ideia de números, medidas, operações mentais, dentre outros. Essas instruções foram apresentadas por classes e por disciplinas. Para a Aritmética, de modo específico, a primeira classe tratava da noção intuitiva sobre os números e cálculos mentais. A segunda classe dizia respeito à tabuada, sugerindo que fosse estudada por meio de cálculos de subtração, adição, divisão e multiplicação e a terceira classe procedeu ao estudo do sistema de medidas e monetário e à resolução de problemas de forma que contextualizassem o 
ensino de aritmética. As sugestões apresentadas foram que o docente utilizasse o contador mecânico e outros meios materiais para a aprendizagem do aluno.

Nota-se que há ausência da memorização como método de estudo. Repudiada pelas orientações da pedagogia intuitiva, dava agora lugar para um ensino que valorizasse a concretização. Assim, o uso de materiais manipuláveis estimularia os sentidos dos alunos e poderia promover a aprendizagem, um discurso bem característico dessa vaga pedagógica, conforme apresentado por Valdemarin e Pinto (2010).

A utilização de materiais concretos foi também tratada no segundo artigo dessa análise, "Nos etiam pro causa nóstra pugnamos", de autoria do professor Argemiro Cavalcante, publicado na Revista do Ensino Primário da Bahia. No número 1, do mês de novembro de 1892, o autor fez críticas aos livros adotados pela diretoria de ensino público para as escolas primárias, que, em sua opinião, iam de encontro a um ensino prático e intuitivo. De acordo com Cavalcante (1892a, p. 8), nas matérias de ensino da escola primária, deveria o ensino de aritmética "[...] ser feito por meio de exercicios praticos, analagos as lecções de cousas por meio de exercicios de calculo oral, com auxilio de quantidades concretas".

Baseando suas reflexões em educadores que assinalavam uma aritmética ensinada de forma prática, este mesmo autor escreveu o artigo "Considerações sobre o ensino de arithmetica e livros para as escolas primárias", no número 2 da Revista do Ensino Primário da Bahia, do mês de dezembro de 1892. Nesse artigo, Cavalcante (1892b) referiu-se ao ensino de leitura e aritmética apontando que as cartas A, B, C e as tabuadas não eram úteis pedagógica e economicamente para a educação. Sua sugestão era que, para a instrução aritmética, fosse comprado um material específico, em quantidade suficiente para que pudesse ser distribuído a todos os alunos da escola primária.

Observa-se que nestes três artigos há uma articulação de uma concepção evolutiva do pensamento da criança, tendo sempre por base o uso de materiais manipuláveis no trabalho pedagógico dos professores da escola primária. O uso didático de materiais no ensino da aritmética mostrou-se uma prática recomendada para que o ensino acompanhasse o desenvolvimento considerado natural da criança, pois deveria estar baseado em "coisas" ligadas à sua vida, como assinala Bastos (2013). 
Defendendo também o uso de objetos concretos no ensino da aritmética nos anos iniciais da escola primária, no ano seguinte, 1893, o artigo "O ensino da arithmetica", de autoria do professor Pedro Celestino, destinado à escola primária, foi publicado na Revista do Ensino Primário da Bahia, em seu número 9. O autor iniciou sugerindo que no estudo dos números o professor fornecesse diversos instrumentos aos alunos em atividades concretas. Como exemplo, Celestino (1893a) referiu às mudanças pelas quais havia passado o contador mecânico, considerado naquela época um instrumento importante e eficiente no ensino de aritmética, podendo ser utilizado até que os alunos dominassem as operações fundamentais.

De acordo com Celestino (1893a), dentre outros instrumentos recomendados para o ensino devido à eficácia profissional de seus criadores, estavam os aritmômetros ${ }^{8}$, porém, este assinala que o professor da escola Politécnica de Zurich, Bagnaux Rambert e outros haviam se manifestado contrários ao uso destes instrumentos nas primeiras noções das operações aritméticas que, segundo eles, confundiam a criança. Entretanto, Celestino (1893a, p. 166) mostrou não concordar com esse posicionamento, afirmando que "supor que não se pode ensinar os primeiros rudimentos dos números, por meio desses instrumentos, equivale ao mesmo que desconhecer as dificuldades da compreensão infantil, no começo de todo aprendizado".

Observa-se que o ensino de aritmética e o modo como os professores da escola primária conduziriam esse ensino com uso do concreto foram preocupações que motivaram Celestino a escrever seu artigo (1893a). Assim, para que pudesse haver essa concretização, a escola precisaria estar aparelhada com materiais para o uso didático-pedagógico nas aulas. E trabalhar com materiais concretos para um ensino intuitivo, que estimulasse os sentidos da criança foi temática de outros dois artigos deste mesmo autor.

No número 10 da Revista do Ensino Primário da Bahia, de agosto de 1893, o artigo "O Ensino da Arithmetica", de Pedro Celestino, abordou instrumentos que estavam sendo utilizados nas instituições de ensino de Nova Iorque, como por exemplo, o Contador de Gould, que, segundo Celestino (1893b), era adequado para realizar diversos cálculos com números inteiros, o que

\footnotetext{
${ }^{8}$ Segundo Celestino (1893a, p. 185), o aritmômetro de áreas foi utilizado com grande proveito nas escolas da Bélgica. Para informações sobre sua composição, leia-se o material disponível no repositório da UFSC. Disponível em: https://repositorio.ufsc.br/handle/123456789/129732. Acesso em: 17 set. 2017.
} 
dispensava anotações do docente no quadro. Este instrumento propiciaria aos alunos realizar diversas combinações numéricas baseadas nas regras da aritmética.

Outro instrumento, o Aritmômetro de Áreas, utilizado em instituições de ensino da Bélgica, foi apresentado por Celestino (1893b). Era constituído:

I. De um contador mecânico comum com 100 esferas coloridas móveis, distribuídas por dezenas sobre 10 varões horizontais.

II. De um quadro de cavilhas, cujo fim é tornar mais compreensível o ensino da numeração dos inteiros e dos números métricos.

III. Das principais medidas do Sistema Métrico em tamanho natural, a saber 1.; um metro linear dividido em decímetros e centímetros; $2 . ;$ um metro quadrado na parte superior do aparelho, 3.; um metro sobre este último; 4.; um decímetro linear dividido em centímetros; 5 .; um decímetro cúbico dividido em centímetros cúbicos; 6.; desenhos de litros, moedas, etc.

IV. Ainda possuia o aparelho uma caixa formando um paralelepípedo retangular de um decímetro de largo e de alto, e de um metro de comprimento, tendo, por consequência, o volume de 10 decímetros cúbicos, ou a centésima parte de um metro cúbico. Esta caixa é dividida em três compartimentos, encerrando o 1. Um decímetro cúbico; o 2.; uma coleção de cavilhas com cabeças arredondadas; o 3.; sólidos servindo para demonstrar a formação do quadrado e do cubo de um número. (CELESTINO, 1893b, p. 186).

Celestino (1893b, p. 186) também menciona o "fraciometro", ou instrumento escolar múltiplo, idealizado pelo barão de Macaúbas, fruto de uma experimentação aplicada ao ensino e composto por nove pedaços. Cada um desses pedaços era de grande utilidade para a educação, quais sejam: "contador mecânico para inteiros; fraciometro, ou contador denominado Froebel para diversas ordens de unidades; aparelho cromático; imprensa escolar; pauta musical; quadro negro, porta mapas e sólidos aritméticos”.

O Contador de Mac-Vicor, utilizado em instituições de ensino dos Estados Unidos, cujo nome homenageia um docente e diretor de uma Escola Normal, também foi apresentado. Com este instrumento, os alunos poderiam realizar atividades dos sistemas básicos de numeração, envolvendo números inteiros ou frações (CELESTINO, 1893b). O autor descreveu as vantagens de seu uso (Figura 01): 
FIGURA 01 - Vantagens do contador Mac-Vicor.

«Entre outras vantagens notam-se as seguintes: 1.; ao praticar um exercicio o professor nada faz que distraia os disctpulos; trabalba em silencio, e pode occupar tambem a attenção em observar o que fazem os alumnos; $2 . ;$ as maiores facilidades para a rapida inspeção occular são oblidas; $3 \cdot$, nenhum tempo é gasto em pronunciar ou escrever exemplos; ao contrario é todo empregado em trabalhar para a obtençãe de resultados promptos; conseguindo-se por tal modo toraar o discipulo exercitado em operaçes numericas sem perda de tenpo; $1 . *$ ordem, actividade $e$ attenção, presas a um assumpto, em um tempo dado, são desenvolvidas no discipulos, $\infty$

Arithmometro de Arens, empregado com grande proveito nas escolas belgas.

Fonte: Celestino, 1893b, p. 185.

Ao que parece, o professor Celestino, tanto no seu primeiro artigo, quanto no seu segundo artigo, sustenta um discurso acerca do ensino de aritmética baseado no método intuitivo que estava sendo mundialmente defendido para a educação, mostrando sua leitura sobre esse movimento pedagógico para os ensinos de aritmética na escola primária, por meio da concretização dos números com utilização de diversos instrumentos já consagrados.

Este mesmo professor, esforçando-se para levar aos professores leitores da Revista do Ensino Primário da Bahia como poderia se dar o uso de diferenciados instrumentos do cálculo na escola primária, em outubro de 1893, no número 12 dessa revista, no artigo "O Ensino da Arithmetica", tratou da importância dos exemplos para o ensino da aritmética e completou:

Desenvolver as faculdades da criança, pondo de parte as abstrações; facilitar os primeiros ensaios do espírito, sem fadiga, sem esforço, de modo que ela passe gradualmente do simples para o composto, do concreto para o abstrato, do exemplo às regras, da generalização às minucias; eis o fim reservado ao contador mecânico, quando trata dos conhecimentos preliminares do cálculo nos cursos infantis. (CELESTINO, 1893c, p. 218).

Para a aprendizagem do conceito dos números pelas crianças dos primeiros anos escolares, defendeu que necessitavam de exemplos que utilizassem coisas materiais para o contato visual e a manipulação, dando como exemplo o contator mecânico ou ábaco. Nesta direção, Celestino (1893c) sugeriu que professor poderia utilizar estes instrumentos em atividades nas aulas com seus 
alunos iniciantes na aprendizagem da aritmética. Apresentou também como sugestão o uso do aritmômetro, explicando: "[...] a metrologia, a física, a leitura, a escrita, a música, a geometria, a geografia, etc., presta o aritmômetro um serviço verdadeiramente apreciável, de modo mais útil e prático; evitando desperdício de tempo, economizando esforços ao discípulo e ao professor" (CELESTINO, 1893c, p. 219).

Para esse autor, estes instrumentos correspondiam às expectativas do ensino e se adequavam a todas as turmas, pois facilitariam a compreensão da aritmética e a aprendizagem desses conceitos, sua aplicação e desenvolvimento em sua formação (CELESTINO, 1893c). O autor mencionou que o contador mecânico estava sendo empregado no ensino do cálculo em países como Alemanha e Estados Unidos, como também os livros didáticos. Segundo suas palavras:

Isto quer dizer que o contador mecânico é ali largamente usado e o cálculo mental objeto de ensino particular em todas as escolas de instrução elementar. Além destes meios mecânicos, há para facilitar o estudo ulterior dos números, excelentes compêndios didáticos, com seus exercícios fáceis e claros, que levam hábil e suavemente o conhecimento maduro à novel inteligência. Os compêndios de Greenleal, Thomson, Ray, Feiter, Veuable e outros são publicados anualmente e consumidos no mercado centenas de edições avultadíssimas. (CELESTINO, 1893c, p. 220)

Em relação aos livros didáticos no Brasil, Celestino (1893c) mencionou que havia sido adotado o livro "Aritmética elementar ilustrada", de Antônio Trajano, para estudantes de séries mais avançadas. Ele explicou que este livro trazia conceitos claros, atividades variadas, metodologia simples, e estava de acordo com as novas diretrizes pedagógicas daquela época. Finalizou, reafirmando que as ideias concretas deveriam ter prioridade no ensino, e esse livro de Trajano poderia propiciar à criança a compreensão dos conceitos aritméticos estudados.

Também em seu terceiro artigo, o professor Celestino deixa claro que o modo mais apropriado de se adaptar à modernidade pedagógica que se colocava, o ensino intuitivo, era por meio do uso de materiais concretos no ensino da aritmética nos primeiros anos de escolaridade. Mostrando que esses instrumentos são múltiplos e que auxiliariam os professores em relação à necessidade de concretização dos números, considerou que era uma forma didático-pedagógica de promover ensinos com suportes didáticos que permitissem a concretização numérica.

Trabalhar com o concreto foi tema de outro artigo direcionado ao ensino primário, e se intitula "Observação aos professores ou adjuntos que se occupam do ensino de arithmetica nas 
classes elementares das escolas do $1^{\circ}$ grau". Foi publicado na Revista Pedagogica do Rio de Janeiro, em julho de 1893, de autoria do professor J. F. Velho da Silva. Este autor apresentou aos professores leitores vinte lições de aritmética, orientações e exemplos de metodologias de ensino que poderiam ser utilizadas nas aulas com as crianças. Silva (1893, p. 287) afirmou:

Os espíritos infantis gostam naturalmente do estudo da Arithmetica: gostam de contar, juntar, tirar, somar ou subtrair, mormente se estas operações forem ensinadas com objetos a vista. O espírito da criança é muitíssimo concretizador e é por isso que o professor deve tomar interesse em que os objetos empregados sejam conhecidos pelas crianças.

Desta forma, Silva (1893) pontuou que, independentemente do conceito estudado, de modo a seguir a ordem natural das coisas, deveria vir o concreto antes do abstrato. Assim, sua sugestão foi para que o docente, utilizando-se de objetos simples nas aulas, instigasse o aluno a identificar tipos de combinações numéricas e propriedades. Em suas palavras, as crianças deveriam ter acesso a uma caixa com objetos como pauzinhos "tornos de sapateiro, fragmentos de phosphoros, feijão, palha, milho, etc. [...]" (SILVA, 1893, p. 287). Para este autor, esses objetos poderiam ser utilizados nas aulas e facilitar o entendimento da aritmética pelas crianças. Sugeriu que o professor iniciasse a aula da seguinte forma:

Estende um dedo: Quantos dedos? "Responde a criança: um". Concretiza a ideia, ensina a cada um deles, a dizer "um dedo". Depois deste primeiro estenderá mais um dedo ou mostrará um objeto qualquer, torno, pau, milho, etc., etc. Dá um traço na pedra. "Quantos traços se acham nesta pedra?" "Um só" respondem os meninos. Ensinar-vos-hei ou ensinarei a cada um de vocês como este giz, que está na minha mão, pode dizer "um", que pode representar um menino, um cubo, uma casa, um pau, finalmente, um objeto qualquer. (SILVA, 1893, p. 287).

Nessa primeira lição, o professor procederia escrevendo na lousa o algarismo 1, e esses mesmos procedimentos poderiam ser replicados para o ensino dos outros números como o número 2; utilizando-se de dois pauzinhos; dois dedos; dois traços etc., afirmou Silva (1983). Assim, a compreensão dos conceitos se basearia, em um primeiro momento, em materiais concretos, e só posteriormente se daria a representação aritmética para a abstração. A partir da quinta lição, as sugestões desse autor foi para que os professores trabalhassem conceitos aritméticos por meio de 
problemas evolvendo as operações. Assim, apresentou até a vigésima lição abordando a adição e a subtração, sugerindo o mesmo padrão, exercícios seguidos de problemas (SILVA, 1983).

Observa-se que Silva (1983) sugere um ensino com uso didático de materiais manipuláveis, um ensino do sistema de numeração que considerasse impreterivelmente objetos e coisas da vida da criança de modo a concretizar o processo e levá-la a interessar-se pela aritmética na escola. Como enfatiza Valente (2008, p. 6), para o ensino intuitivo da Aritmética, "seixos, canetas, tornos, livros etc deveriam ganhar as salas de aula como elementos simples de contato e experimentação a ser travada com os números".

Focando no empenho dos professores, através de atividades práticas, para ensinar aos alunos a aplicação da soma e da subtração, o artigo de autoria de Kiddle, Harrison e Calkins, intitulado "Manual de Methodos" aborda o ensino da aritmética em lições e orientações para escola primária. Publicado no Tomo V, que reuniu os números 25, 26 e 27 da Revista Pedagogica do Rio de Janeiro, no ano de 1893, o artigo traz o discurso de seus autores no qual defenderam um ensino das estruturas da palavra em exercícios orais e escritos sobre as definições dos conceitos aritméticos estudados.

De acordo com Kiddle, Harrison e Calkins (1893), os professores deveriam utilizar "lições sobre objetos" com as crianças a partir de objetos, permitindo-lhes a manipulação, observação, comparação, classificação e descrição de qualquer objeto. Esse tipo de atividade facilitar-lhes-ia a aprendizagem dos conteúdos (Figura 02).

FIGURA 02 - Lições sobre objetos.

\section{Liçōes sobre objectos.-Os diversos pontos a que so referem} as liçôes sobre objectos desenvolvem muito mais a intelligencia das crianças do que os exercicios exclusivos de leitura, escripta e aritbmetica.

Fonte: Kiddle, Harrison e Calkins (1893, p. 219).

Observa-se que em todas as atividades sugeridas por Kiddle, Harrison e Calkins (1893) a criança teria oportunidade de relacionar a aritmética ao seu cotidiano, possibilitando ao docente refletir sobre a forma de ensinar em sala de aula. Para Bastos (2013), a lição de coisas envolvia 
tudo o que dizia respeito à vida da criança e aos fenômenos da natureza, o que incluía lições de observação, de informação, de palavras. Neste caso, Kiddle, Harrison e Calkins (1893) denominaram-nas "lições sobre objetos", evidenciando o modo de tratar o ensino da Aritmética pelo ideário da pedagogia intuitiva.

Sugerindo o uso de material concreto para o ensino da Aritmética, o professor Oscar Thompson publicou um artigo sob o título de "Arithmetica Elementar", no número 1 da revista $A$ Eschola Publica do estado de São Paulo, em julho de 1893. O autor iniciou esse artigo defendendo que o estudo da aritmética estimulava e organizava a capacidade de raciocínio dos alunos, focava a atenção em atividades mentais e dependia dos procedimentos de ensino.

Thompson (1893) discorreu sobre a importância de o estudo dos números ir além da forma representativa e, em um primeiro momento, que o aluno os considerasse como grupos de objetos. Assim, mencionou que as dificuldades dos alunos em aritmética poderiam ser superadas se o professor utilizasse em suas aulas objetos como pequenas tábuas ou figuras. Apresentou uma lição com sugestões de procedimentos para o professor da escola primária, de modo que pudesse utilizar como objeto de estudo as tabuinhas e figuras (Figura 03).

A sugestão em uma primeira lição era o professor solicitar que os alunos retirassem uma tabuinha e, na sequência, respondessem aos seus questionamentos: “João, quantas tabuinhas tem você? Eu tenho uma tabuinha”. Os alunos, um por vez, apresentariam o objeto a todos os presentes na aula (THOMPSON, 1893, p. 5).

FIGURA 03 - Descrição de como poderia ser a atividade.

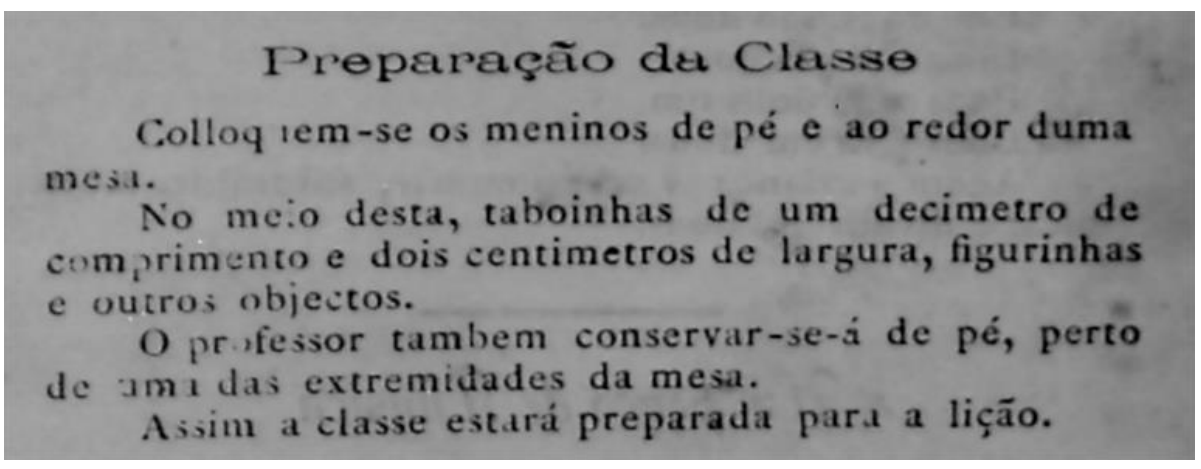

Fonte: Thompson, 1893, p. 5. 
A preocupação de Thompson (1983), ao que parece, era a concretização do estudo dos números para que fizesse sentido a construção desse conceito de modo que os algarismos não fossem considerados como meros símbolos pelas crianças, mas como grupos de objetos. De acordo com Valente (2015), a aritmética é constituída de símbolos que representam os objetos matemáticos, e os materiais manipuláveis pelos alunos subsidiavam um ensino concreto. Ainda, o novo método de ensino, o método intuitivo, conforme menciona Valdemarin (2004), deveria ser ativo e concreto e baseado nas lições de coisas. Esse novo método de ensino deveria utilizar novos materiais.

A utilização de materiais concretos para o estudo das operações aritméticas foi o cerne do artigo "Arithmetica", de autoria de Arnaldo Barreto, publicado no número 4 da revista A Eschola Publica de São Paulo, em 1896. Nesse artigo, consta um roteiro de atividades envolvendo a aritmética que iniciou orientando os professores a solicitar a cada aluno a disposição de uma quantidade de tábuas que desejasse sobre a mesa, não ultrapassando dez, e fizesse perguntas, de modo a realizar somas e subtrações mentalmente (Figura 04).

FIGURA 04 - Perguntas que poderiam ser feitas para os alunos.

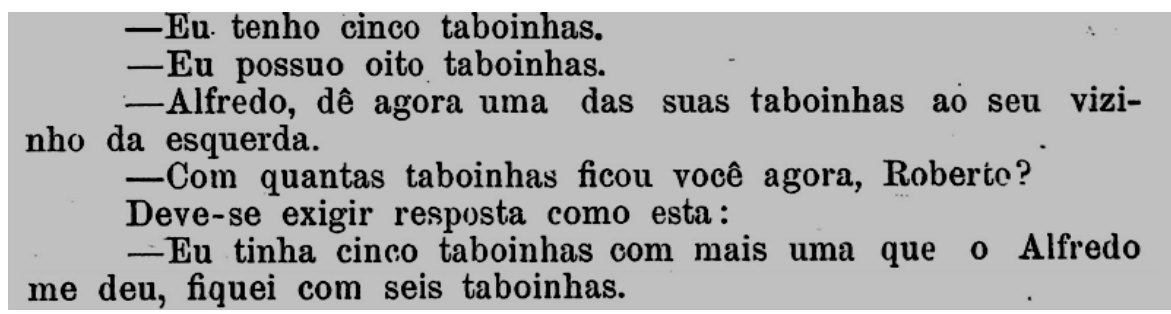

Fonte: Barreto, 1896, p. 309.

Para esse autor, o mais adequado era que houvesse duas aulas de aritmética todos os dias, e que, na segunda aula, fossem utilizados tornos que auxiliassem a efetuar as operações aritméticas. O autor exemplifica como poderia ser essa representação (Figura 05). 
FIGURA 05 - Representação na lousa de operação com tornos.

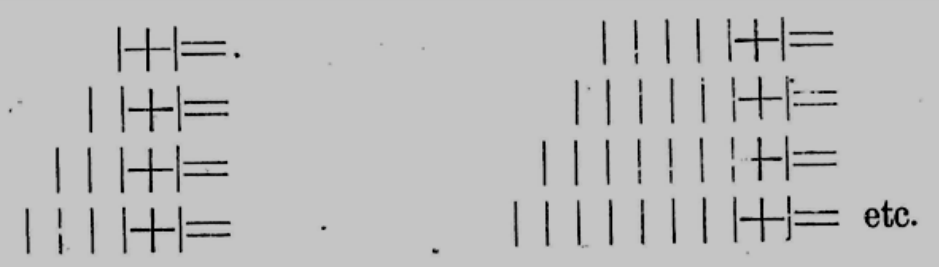

Fonte: Barreto, 1896, p. 309.

$\mathrm{Na}$ aula com tornos, a sugestão de Barreto (1896) foi para que o professor solicitasse aos alunos que posicionassem os tornos sobre a carteira, replicando as operações representadas na lousa e, posteriormente, apresentassem o que haviam feito. Em seguida, poderia o professor propor diversos exercícios aos alunos. Esse mesmo tipo de procedimento foi indicado pelo autor em uma segunda parte das atividades envolvendo a operação multiplicação. Ele ainda sugeriu que o estudo da divisão fosse realizado com esse mesmo material.

Essa recorrência a objetos manipuláveis para representações do mundo real por meio de materiais concretos continua presente nos artigos do início do século XX, como no artigo publicado em 1902, na Revista de Ensino do Estado de São Paulo, número 1, e intitulado "Cartas de Parker: para o ensino de aritmética nas escolas primárias" de autoria de Joaquim Luiz Brito (J. B $\left.{ }^{9}\right)$. Para esse autor, disponibilizar as Cartas de Parker ${ }^{10}$ nessa revista contribuiria com os colegas professores e alunos da escola primária, pois não estavam ainda à venda no mercado. Sua sugestão foi para que os professores copiassem cada carta dessas na lousa, e apresentou explicações de como poderiam ser utilizadas nas aulas de aritmética.

A título de exemplo, o estudo da primeira Carta de Parker, de acordo com Brito (1902), poderia iniciar pela representação por meio de uma gravura de diversas classes de objetos, animais, dentre outras. Este autor recomendou que os professores aplicassem para cada criança um teste de conhecimentos em quatro passos, objetivando conhecer o que já entendiam dos números. No

\footnotetext{
${ }^{9}$ Segundo Valente (2017) essa assinatura é de autoria de Joaquim Luiz Brito, neste texto Brito (1902).

${ }^{10}$ Segundo Valente (2015, p. 608), as "Cartas de Parker constituem um dispositivo didático, publicadas na Revista de Ensino e, posteriormente, transformadas em pranchas - cerca de 50 - para uso dos professores primários na condução das primeiras operações fundamentais da aritmética. Junto às pranchas, também conhecidas como Mapas, há orientações aos professores em cada uma delas".
} 
primeiro, o aluno, sem dizer o nome dos objetos, indicaria a quantidade a ele apresentada pelo professor, conforme figura 06.

FIGURA 06 - Primeira Carta de Parker, primeiro passo.

1. PAsso - Numeros sem seus nomes. O mestre apresenta quantidades de cousas $\left(2,3^{\prime}\right.$ ou 4$)$ palitos, lapis, canetas, etc., $\Theta$ convida o alumno a trazer tantas dessas cousas (o numero mos trado). Faça tantos signaes; aponte para tantos lapis sobre a carteira. A creança deve conhecer um numero sem conhecer seu nome.

Fonte: Brito, 1902, p. 36.

No segundo passo, o professor poderia apresentar objetos aos seus alunos e solicitar que indicassem a quantidade, por exemplo, "mostre tantos palitos, tantas canetas, etc. sobre a mesa" (BRITO, 1902, p. 36). No $3^{\circ}$ e $4^{\circ}$ passos, o professor perguntaria aos alunos a quantidade e o nome dos objetos, recordando as quantidades de cada tipo de objetos. A partir dos resultados, poderia o professor prosseguir com os estudos envolvendo outras características dos objetos, como o formato, a cor, dentre outras (BRITO, 1902).

Essas sugestões para que o professor apresentasse a Carta de Parker aos alunos e os orientasse para a apresentação de quantidades correspondentes de objetos acompanharam quase todas as cartas apresentadas por Brito (1902). As crianças, após observações e manipulações desses objetos, representariam as respectivas quantidades com desenhos na lousa, orientados pelo professor. Além dessas orientações, em algumas cartas, foram dadas sugestões ao professor, no sentido de reforçar as simbologias utilizadas nas operações aritméticas, o que levaria a criança a compreender que há diferentes modelos dessas representações.

Em um momento em que, segundo esse autor, já estavam sendo obtidos bons resultados nas escolas primárias com a utilização das Cartas de Parker, e ainda não havia esse material disponível no mercado, seu texto poderia auxiliar os colegas professores a utilizar as Cartas de Parker no ensino de aritmética. Para Valente (2015), a ampla circulação que teve o material Cartas de Parker é reflexo do novo modo de organizar o curso primário no estado de São Paulo. Vale salientar a criação dos grupos escolares, em que esse estado é protagonista em 1983, o que, 
juntamente com a chegada da pedagogia intuitiva, pode justificar essa ampla aceitação de um material estruturado no ensino da aritmética na escola primária.

A necessidade de utilização de métodos práticos envolvendo uso de materiais manipulativos para a soma, a subtração e outras operações, foi a temática do artigo "Arithmetica Preliminar", de autoria de Flávio Lopes Monteiro, publicado no número 3 da Revista de Ensino de São Paulo, do ano de 1916. O autor traz que o estudo da aritmética nos primeiros anos da escola primária deveria iniciar com os números e depois as operações fundamentais. Monteiro (1916) defendeu que essas operações realizadas em situações de observação poderiam auxiliar na compreensão das crianças, que entenderiam, por exemplo, a adição, conforme apresentado na Figura 07.

FIGURA 07 - Exemplo Adição envolvendo objetos.

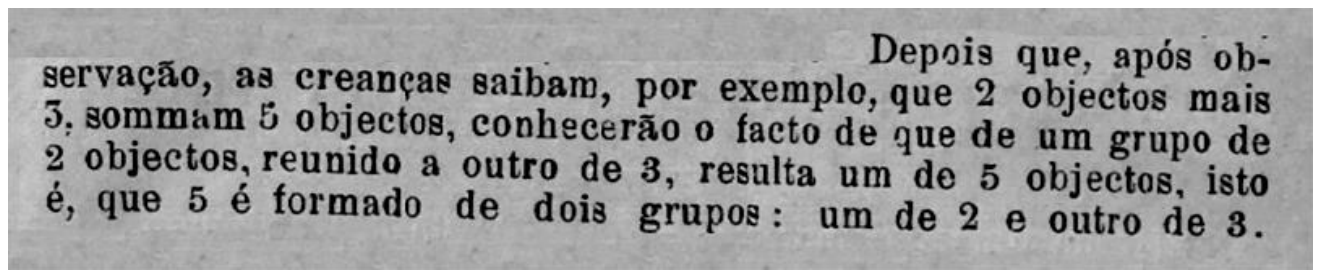

Fonte: Monteiro, 1916, p. 30.

Finalizando, Monteiro (1916) afirmou que essa metodologia para ensinar as operações às crianças poderia facilitar sua compreensão. Ao professor caberia conduzir seus alunos a efetuarem variados cálculos aritméticos, e, posteriormente, poderiam resolver cálculos de forma autônoma, alcançando o objetivo do ensino.

Embora esse artigo tenha sido publicado no início de um período em que as ideias da Escola Nova já adentravam no Brasil por meio de ações que mostravam os anseios de professores para que o ensino fosse modernizado, reflete ainda características de um ensino intuitivo. E nos preceitos da pedagogia intuitiva pode-se dizer que a Aritmética deveria ser ensinada com materiais onde o ensino fosse o mais concreto possível. 


\section{TECENDO ANÁLISES E CONCLUSÕES}

Retomando o objetivo deste estudo, buscou-se analisar as orientações sobre o uso didático de materiais no ensino de aritmética na escola primária sob a lente de artigos publicados, entre 1891 e 1916, em revistas pedagógicas de diferentes estados brasileiros. Os anos 1890 no Brasil foram marcados pelo início da Primeira República, quando a educação passou a ser a esperança para resolver problemas nacionais de diferentes ordens. A educação para as primeiras séries de escolaridade também ficou em evidência com a criação dos grupos escolares. No âmbito de tantas mudanças, os métodos de ensino também tomaram parte e, no método intuitivo, a "Lição de Coisas" foi uma prática recomendada no ensino que facilitaria a compreensão dos alunos por se basear em "coisas" ligadas à sua vida e aos acontecimentos naturais, conforme Bastos (2013).

Não obstante, características da vaga pedagógica intuitiva foram representadas pelos autores dos artigos analisados, que mostraram e defenderam que os primeiros passos rumo às etapas mais avançadas da aritmética deveriam impreterivelmente incluir o contato físico da criança com materiais manipuláveis que lhe permitissem a observação, experimentação para posterior abstração dos conceitos aritméticos estudados e o acesso ao saber sistematizado posteriormente. No entanto, é perceptível que o convencimento dos professores leitores nos artigos passava pela certificação de que sem a aquisição do conhecimento por meio de materiais concretos, não seria possível prosseguir estudos dos temas aritméticos.

Neste contexto, os autores dos artigos da década de 1890 orientaram os professores leitores a utilizarem uma diversidade de materiais nas aulas de aritmética. A começar pela Revista do Ensino de Alagoas, publicada em 1891, a sugestão foi para que os docentes trabalhassem a ideia de números por meio do contador mecânico e outros objetos. Há também aqueles artigos, como os de autoria de Cavalcante (1892a; 1892b), publicados na Revista do Ensino Primário da Bahia, que expressaram críticas aos livros didáticos que não traziam sugestões de aulas práticas. A sugestão dada foi que o Estado se preocupasse em enviar para as escolas materiais didáticos específicos para o ensino da aritmética, em quantidade suficiente para o número de alunos.

Ainda dessa década, os artigos Celestino (1893a; 1893b;1893c), recomendaram o uso de diferenciados instrumentos de ensino tidos naquela época como inovadores para o ensino dos cálculos. O livro didático de Trajano foi outro material sugerido como apoio ao ensino da 
aritmética, por considerá-lo adequado, posto que apresentava metodologias com atividades diversificadas. Silva (1893) e Thompson (1993) têm uma comum preocupação com a assimilação dos conceitos aritméticos pela criança a partir de situações que envolvessem o uso didático de materiais nas aulas para a contagem e a importância do uso de materiais concretos também foi defendida por Kiddle, Harrison e Calkin (1893), e Barreto (1896) sugeriu situações-problema a partir de objetos apresentados pelo professor.

Observa-se, assim, um direcionamento para o ensino por meio dos sentidos, característica própria do método intuitivo, conforme apresentado por Aranha (1996). De acordo com Valente (2015), ao final do século XIX o "ensino primeiro no concreto" foi incorporado e se tornou um elemento da cultura escolar. E assim, conforme a abordagem efetuada neste estudo, as orientações didático-pedagógicas para o uso de materiais manipuláveis da vida real da criança, nominados por materiais concretos, constituía-se, portanto, em uma forma prática do ensino intuitivo nas aulas da escola primária.

Buscando tecer essas análises com base em Valente (2015), foi no impacto da vaga intuitiva para a educação escolar que construiu-se a representação de que era preciso concretizar, utilizando as lições de coisas. E assim, a interpretação dos docentes, ao afirmarem que trabalhavam "primeiro no concreto", advém da manipulação de objetos do mundo real "para representações desse mundo" por meio desses materiais. Como consequência, conforme mostrou Bastos (2013), essa valorização do método intuitivo e o ensino através da lição de coisas vieram, posteriormente, estimular uma diversificada produção de recursos didáticos.

As Cartas de Parker, por exemplo, sugeridas por Brito (1902), foi um recurso didático que passou da descrição em artigos para impressão em pranchas manipuláveis pelos alunos, com instruções de uso, para as primeiras operações fundamentais da aritmética na escola primária. Um ensino gradativo das operações elementares foi sugerido por Monteiro (1916), por meio de métodos práticos subsidiados pelo uso didático de materiais manipuláveis.

Trata-se de recomendações de uso didático de materiais em um ensino intuitivo que foi considerado um caminho para a educação dos sentidos, pelas coisas e pela experiência da criança (VALDEMARIN, 2004). Compreende-se, assim, que essas sugestões de uso de materiais propiciando a visualização, a observação e a compreensão da aritmética pela criança, características 
do método intuitivo, podem ter tornado o ensino do cálculo aritmético na escola primária, mais compreensível pela criança.

Em síntese, a questão pedagógica central da pedagogia intuitiva abordada pelos autores dos artigos analisados envolveu sugestões e orientações, para os professores do curso primário, do desenvolvimento de atividades didático-pedagógicas com o uso de objetos ou "coisas" para o ensino de aritmética. No entanto, saindo do plano das sugestões e orientações veiculadas pela imprensa pedagógica e pensando na prática de sala de aula, outros tipos de fontes como cadernos escolares, cadernos de professores, dentre outros poderiam ser analisados em próximos estudos que tenham como norteadoras questões como: Estes materiais chegaram às escolas brasileiras? As professoras primárias tinham domínio de conhecimento sobre o método intuitivo de ensino que se estava propondo?

Em suma, muitos são os caminhos que a escola trilhou e continua trilhando na edificação da cultura escolar e as ações dos atores em prol do ensino sempre acompanham as vagas pedagógicas que vêm e que vão, mas deixam suas marcas refletidas nas representações e apropriações efetuadas pelos professores em sua jornada educacional. Assim, de acordo com Valente (2015, p. 608), na análise dos elementos presentes na cultura escolar é "necessário interpretar os sentidos que uma norma ou prática têm no movimento de existência e transmissão dessa cultura, cultura escolar"

\section{REFERÊNCIAS}

ARANHA, M. L. A. História da educação. 2. ed. São Paulo: Moderna, 1996.

BARRETO, A. Arithmetica. A Eschola publica, São Paulo, v. 1, n. 4, p. 309-313, dez. 1896. Disponível em: https://repositorio.ufsc.br/handle/123456789/126739. Acesso em: 27 jan. 2018.

BASTOS, M. H. C. Método intuitivo e lições de coisas por Ferdinand Buisson. Hist. Educ. (Online), Porto Alegre, v. 17, n. 39, p. 231-253, jan./abr. 2013. Disponível em: http://www.scielo.br/pdf/heduc/v17n39/a13v17n39.pdf. Acesso em: 05 fev. 2018.

BASTOS, M. H. C. Educação Infantil e ensino intuitivo: a contribuição de Marie Pape-Carpantier (1815-1878). Conjectura: filosofia e educação, v. 15, n. 3, p. 14-46, 2010. Disponível em: http://www.ucs.br/etc/revistas/index.php/conjectura/article/view/507/395. Acesso em: 05 fev. 2018. 
BOMENY, H. Reformas educacionais. In: ABREU, A. A. Dicionário histórico-biográfico da Primeira República (1889-1930). 2010. Disponível em: http://cpdoc.fgv.br/sites/default/files/verbetes/primeirarepublica/REFORMAS\%20EDUCACIONAIS\%20.pdf. Acesso em: 18 fev. 2018.

BRASIL. Decreto $n^{\circ} 981$, de 8 de novembro de 1890. Aprova o Regulamento da Instrucção Primaria e Secundaria do Districto Federal. Disponível em:

https://www2.camara.leg.br/legin/fed/decret/1824-1899/decreto-981-8-novembro-1890-515376publicacaooriginal-1-pe.html. Acesso em: 17 set. 2018.

BRITO, J. L. S. Cartas de Parker: para o ensino de arithmetica nas escolas primarias. Revista de Ensino, São Paulo, v. 1, n. 1, p. 35-46, abr. 1902. Disponível em: https://repositorio.ufsc.br/xmlui/handle/123456789/98842. Acesso em: 27 jan. 2018.

CARVALHO, M. M. C. Livros e revistas para professores: configuração material do impresso e circulação internacional de modelos pedagógicos. In: PINTASSILGO, J.; FREITAS, M.C.; MOGARRO, M. J.; CARVALHO, M. M. C. História da Escola em Portugal e no Brasil. Circulação e apropriação de modelos culturais. Lisboa: Colibri, 2006.

CAVALCANTE, A. Considerações sobre o ensino de leitura e arithmetica. Revista do Ensino Primário, Salvador, v. 1, n. 02, p. 21-23, dez. 1892b. Disponível em: https://repositorio.ufsc.br/handle/123456789/129726. Acesso em: 17 jan. 2018. CAVALCANTE, A. Nos etiam pro causa nóstra pugnamos. Revista do Ensino Primário, Salvador, v. 1, n. 1, p. 1-9, nov. 1892a. Disponível em https://repositorio.ufsc.br/handle/123456789/129725. Acesso em: 17 jan. 2018.

CELESTINO, P. O ensino de arithmetica. Revista do Ensino Primário, Salvador, v. 1, n. 10, p. 185-186, ago. 1893b. Disponível em: https://repositorio.ufsc.br/handle/123456789/129732. Acesso em: 27 jan. 2018.

CELESTINO, P. O ensino de arithmetica. Revista do Ensino Primário, Salvador, v. 1, n. 12, p. 218-220, out. 1893c. Disponível em: https://repositorio.ufsc.br/xmlui/handle/123456789/129734. Acesso em: 31 mar. 2018.

CELESTINO, P. O ensino de arithmetica. Revista do Ensino Primário, Salvador, v. 1, n. 9, p. 164-166, jul. 1893a. Disponível em: https://repositorio.ufsc.br/handle/123456789/129731. Acesso em: 17 fev. 2018.

CHARTIER, R. A história Cultural: entre práticas e representações. Lisboa: Difel, 1990.

CHARTIER, R. O mundo como representação. Estudos avançados, São Paulo, v. 11, n. 5, p. $172-$ 191, jan./apr. 1991. Disponível em: http://www.scielo.br/pdf/ea/v5n11/v5n11a10.pdf. Acesso em: 17 fev. 2018. 
CURY, C. R. J. A desoficialização do ensino no Brasil: a Reforma Rivadávia. Educação \& Sociedade, v. 30, n. 108. p. 717-738, 2009. Disponível em:

http://www.scielo.br/pdf/es/v30n108/a0530108.pdf. Acesso em: 10 fev. 2018.

FARIA FILHO, L. M.; VIDAL, D. G. Os tempos e os espaços escolares no processo de institucionalização da escola primária no Brasil. Revista Brasileira de Educação, n. 14. p. 19-34. mai./jun./ago. 2000. Disponível em: http://www.scielo.br/pdf/rbedu/n14/n14a03.pdf. Acesso em: 15 jan. 2018.

INSTRUÇÕES para a organização do ensino das escolas primárias. Revista do Ensino, Maceió, v. 1, n. 1, p. 5-16, maio 1891. Disponível em: https://repositorio.ufsc.br/handle/123456789/179870. Acesso: 18 fev. 2018.

KIDDLE, H.; HARRISON, T.; CALKINS, N. A. Manual de Methodos. Revista Pedagógica, Rio de Janeiro, n. 25/26/27, p. 215-227, set. 1893. Disponível em: https://repositorio.ufsc.br/handle/123456789/158562. Acesso em: 04 jan. 2018.

MONTEIRO, F. L. Aritmetica preliminar. Revista de Ensino, São Paulo, v. 15, n. 3, p. 29-32, dez. 1916. Disponível em: https://repositorio.ufsc.br/handle/123456789/130206. Acesso em: 15 jan. 2018.

NÓVOA, A. A imprensa de educação e ensino: repertório analítico. Colecção Memórias da Educação. Lisboa: Instituto de Inovação Educacional, 1993.

OLIVEIRA, M. A. D. A aritmética escolar e o método intuitivo: um novo saber para o curso primário (1870 - 1920). Universidade Federal de São Paulo. São Paulo, 2017. 280p. Disponível em: https:// repositorio.ufsc.br/handle/123456789/178956. Acesso em: 05 de maio de 2018. PINHEIRO, N. V. L.; VALENTE, W. R. A Produção da Matemática na e para a escola primária: a constituição de uma aritmética sob medida. Revista Educação Matemática em Foco, v. 7, n. 1, p. 2-21, 2018. Disponível em: https://repositorio.ufsc.br/handle/123456789/189546. Acesso em: 12 de maio de 2018.

SAVIANI, D. As concepções pedagógicas na história da educação brasileira. Texto elaborado no âmbito do projeto de pesquisa "O espaço acadêmico da pedagogia no Brasil", financiado pelo CNPq, para o "projeto 20 anos do Histedbr". Campinas, 25 ago. 2005. Disponível em: http://www.histedbr.fe.unicamp.br/navegando/artigos_pdf/Dermeval_Saviani_artigo.pdf. Acesso em: 23 de maio de 2018.

SAVIANI, D. et al. O legado educacional do século XX no Brasil. Campinas: Autores Associados, 2004.

SEKI, A. L. S.; MACHADO, M. C. G. A disciplina de instrução moral e cívica na Reforma educacional de Benjamin Constante de 1890. Jornada do HISTEBR, VIII, 2008. 
SILVA, J. F. V. Observação aos professores ou adjuntos que se ocupam do ensino da arithmetica nas classes elementares das escolas do $1^{\circ}$ gra’o. Revista Pedagógica, Rio de Janeiro, p. 287-302, 1893. Disponível em: https://repositorio.ufsc.br/xmlui/handle/123456789/130209. Acesso em: 15 abr. 2018.

SOUZA, R. F. Objetos de ensino: a renovação pedagógica e material da escola primária no Brasil, no século XX. Educar em Revista, Curitiba, n. 49, p. 103-120, jul/set. 2013. Disponível em: http://x viiseminariotematico.paginas.ufsc.br/textos-de-referencia. Acesso em: 12 mar. 2019.

THOMPSON, O. Arithmetica elementar. A Eschola Publica, São Paulo, v. 1, n. 1, p. 5-6, jul. 1893. Disponível em: https://repositorio.ufsc.br/xmlui/handle/123456789/13360. Acesso em: 27 jun. 2018.

VALDEMARIN, V. T. Estudando as lições de coisas: análise dos fundamentos filosóficos do método de ensino intuitivo. Campinas, SP: Autores Associados, 2004.

VALDEMARIN, V. T. Lições de coisas: concepção científica e projeto modernizador para a sociedade. Cadernos Cedes, ano XX, no 52, novembro/2000. Disponível em:

https://repositorio.unesp.br/bitstream/handle/11449/28249/S010132622000000300006.pdf; sequence=1. Acesso em: jun. 2019.

VALDEMARIN, V. T.; PINTO, A. A. Das formas de ensinar e conhecer o mundo: lições de coisas e método de ensino intuitivo na imprensa periódica educacional do século XIX. Revista Educação em Questão, Natal, v. 39, n. 25, p. 163-187, set./dez. 2010. Disponível em: https://periodicos.ufrn.br/educacaoemquestao/article/view/4018. Acesso em: jun. 2019.

VALENTE, W. R. "Matemática? Eu trabalho primeiro no concreto": elementos para a história do senso comum pedagógico. Ciênc. Educ., Bauru, v. 23, n. 3, p. 597-611, 2017. Disponível em: http://www.scielo.br/pdf/ciedu/v23n3/1516-7313-ciedu-23-03-0597.pdf. Acesso em: 15 jan. 2018.

VALENTE, W. R. O ensino intuitivo de aritmética e as cartas de Parker. In: Congresso Brasileiro de História da Educação. O ensino e a pesquisa em história da educação UFS/UNIT. Aracajú, 2008. Disponível em: http://sbhe.org.br/novo/congressos/cbhe5/pdf/528.pdf. Acesso em: 12 jan. 2018.

VALENTE, W. R. A constituição do elementar matemático: uma análise de programas de ensino (São Paulo, 1890-1950). Educação Unisinos, v. 19, n. 2, p. 196-205, 2015. Disponível em: http://revistas.unisinos.br/index.php/educacao/article/view/edu.2015.192.04/4705. Acesso em: 12 set. 2019.

Recebido em: 04 de junho de 2019 Aceito em: 02 de novembro de 2019 